\title{
RETRATOS DA EJA NA AMAZÔNIA MARAJOARA: DESAFIOS DO ENSINO DA LÍNGUA INGLESA NA EDUCAÇÃO ESCOLAR QUILOMBOLA
}

\author{
Karley dos Reis Ribeiro ${ }^{1}$ \\ Raquel Amorim dos Santos ${ }^{2}$ \\ Camila de Cássia Brito ${ }^{3}$
}

\begin{abstract}
RESUMO
O presente estudo se propôs a discutir o ensino da Língua Inglesa (LI) para alunos da Educação de Jovens e Adultos (EJA), na perspectiva da Educação Escolar Quilombola (EEQ), em uma escola quilombola do município de Salvaterra da Amazônia Marajoara. A pesquisa analisou o ensino da LI e seus desdobramentos para a EEQ, permitindo evidenciar outras perspectivas para o ensino do idioma. Utilizou-se a análise interpretativista e pesquisa bibliográfica especializada da área. A pesquisa é de natureza qualitativa e de cunho interpretativista, e os aportes teóricos que embasaram a análise dos dados foram: Pennycook (1998), Rajagopalan (2003), Moita Lopes (2002; 2005), entre outros. Os resultados da pesquisa evidenciaram que as questões étnico-raciais nas aulas de LI na EJA da EEQ é um campo desafiador para alcançar a qualidade do ensino da LI na proposta da EEQ. A necessidade de formação continuada dos professores de LI para as relações étnico-raciais é uma necessidade emergencial, pois os dados indicaram que os desafios estão associados majoritariamente as práticas pedagógicas do professor de LI.
\end{abstract}

Palavras-chave: Educação Escolar. Quilombola. EJA. Língua Inglesa.

\section{PORTRAYING EJA IN MARAJOARA-AMAZON: CHALLENGES OF TEACHING ENGLISH IN A QUILOMBOLA EDUCATIONAL CONTEXT}

\begin{abstract}
The current study aimed to discuss the teaching of the English Language (EL) for students of Youth and Adult Education (EJA) from the perspective of Quilombola School Education (EEQ) in a quilombola school at Salvaterracity, in the Marajoara Amazon. The research analyzed the teaching of LI and its consequences for EEQ, allowing to highlight other perspectives for language teaching. We used interpretative analysis and specialized bibliography of the area. The researchis of a qualitative nature and of na interpretative nature, and the theoretical contributions that supported the data analysis were: Pennycook (1998), Rajagopalan (2003), Moita Lopes (2002; 2005), and anothers. The results of the research showed that the ethno-racial issues in the classes of EL in the EEQ EJA is a challenging

\footnotetext{
${ }^{1}$ Possui graduação em Letras - Inglês pela Universidade Federal do Pará (2012). Possui graduação em Pedagogia pela Faculdade Educacional da Lapa (2019). Especialista em Tradução e Interpretação do Inglês e Português pela Faculdade Integrada Brasil Amazônia (2015). Mestrando do Programa de Pós Graduação em Linguagens e Saberes na Amazônia (PPLSA) Pela Universidade Federal do Pará (UFPA). E-mail: karley@ufpa.br.

${ }^{2}$ Doutora em Educação pela Universidade Federal do Pará (UFPA), Linha de Pesquisa: Educação: Currículo, Epistemologia e História, Mestre em Educação (UFPA), Linha de Pesquisa: Currículo e Formação de Professores. Professora Adjunta da Universidade Federal do Pará, Campus Universitário de Bragança, Faculdade de Educação. Especialista em Currículo e Avaliação na Educação Básica pela Universidade do Estado do Pará (UEPA). Atualmente, Coordenadora do Programa de Pós-Graduação em Linguagens e Saberes na Amazônia (PPLSA). Professora Permanente do PPLSA. E-mail: rakelamorim@yahoo.com.br

${ }^{3}$ Mestranda no Programa de Pós Graduação em Linguagens e Saberes na Amazônia (UFPA). Especialista em Gestão de Unidades de Informação pelo Instituto de Pós Graduação e Cursos - IPGC- (2018). Bacharel em Biblioteconomia pela Universidade Federal do Pará (2013). Membro do Grupo Universitário de Educação de Jovens e Adultos - GUEAJA do Campus Universitário de Bragança/UFPA.E-mail: camilacbrito@ufpa.br
} 
field to reach the quality of the teaching of EL in the EEQ proposal. The need for continuing education of IL teachers for ethnic-racial relations is na emergency need, as the data indicated that the challenges are mostly associated with the pedagogical practices of the EL teacher.

Keywords: School Education. Quilombola. EJA. English Language.

Data de submissão: 29.09 .2020

Data de aprovação: 26.12 .2020

\section{INTRODUÇÃO}

Este estudo analisa a disciplina de Língua Inglesa (LI) da Educação de Jovens e Adultos (EJA) na perspectiva da Educação Escolar Quilombola (EEQ) na comunidade quilombola de Vila União do município de Salvaterra, da Amazônia Marajoara ${ }^{4}$. Pesquisas recentes na área da educação brasileira apontam a necessidade de descortinar olhares sob as práticas socioeducativas para uma ação pedagógica inclusiva e mais próxima das identidades dos alunos da EJA (ARROYO, 2011; PENNYCOOK, 1998; RAJAGOPALAN, 2003). Por essa razão, propusemos a entender quais os desafios existentes no ensino de Língua Estrangeira (LE) - LI em uma turma de EJA do Ensino Fundamental - Anos Finais de uma escola quilombola do município de Salvaterra da Amazônia Marajoara.

O ensino de LI no Brasil tem se tornado uma tarefa desafiadora para professores e alunos no âmbito da educação pública, sobretudo para a EJA. Em linhas gerais, pesquisas de British Council (2015) apontam que o ensino da LI na escola pública apresenta desafios estruturais e funcionais. Nesse interim, percebe-se que há falta de materiais didáticos voltados para a realidade dos educandos, ausência de um ambiente propício para a aprendizagem em LI, carga horária insuficiente para o ensino do idioma e professores com baixa proficiência em LI, e até mesmo com escasso conhecimento linguístico do idioma, e tais questões têm implicado indiretamente na qualidade do ensino aprendizagem de LI na escola pública.

$\mathrm{Na}$ EJA essa realidade atravessa tempos e espaços que dificultam a qualidade do ensino da LI para jovens e adultos. O ensino do idioma apresenta-se bastante complexo e desafiador para muitos estudantes da EJA, uma vez que boa parte deles não são alfabetizados em sua língua materna, dificultando o aprendizado na LI. Além disso, a maioria dos professores de LI que atuam na EJA não possuem formação voltada para o ensino do idioma nessa modalidade de ensino, e são habituados a ensinarem o idioma a partir de suas crenças pedagógicas (BRITISH COUNCIL, 2015; ARROYO, 2011).

O ensino da LI é indispensável para o desenvolvimento de qualquer educando no mundo globalizado, caracterizando uma condição essencial para a inclusão nas sociedades modernas, definida por uma sociedade assentada por diversas identidades sociais. Na Amazônia Marajoara, essa diversidade é marcada pela presença de comunidades indígenas, ribeirinhas, camponesas e quilombolas, nas quais precisam compreender a importância do aprendizado do idioma, para assim terem mais chances de inclusão nesse mundo globalizado.

Na Amazônia Marajoara os quilombos são entendidos como povos ou comunidades tradicionais, "[...] grupos culturalmente diferenciados que se reconhecem como tais; [...] possuidores de formas próprias de organização social; detentores de conhecimento, tecnologias, inovações e práticas geradas e transmitidas pela tradição" (BRASIL, 2012, p. 4),

\footnotetext{
${ }^{4}$ O Termo Amazônia Marajoara é entendido como o arquipélago da ilha do Marajó, localizado no estado do Pará, compreendido por 15 municípios do território. O recorte espacial é o município de Salvaterra, concebido da necessidade geográfica de entender os diferentes movimentos sociais, políticos, ideológicos, religiosos, econômicos e culturais que constituíram as diferentes visões acerca do Marajó. O termo produz uma representação dos amazônidas presentes no arquipélago do Marajó, como uma forma de reproduzir a identidade marajoara a partir dos diversos recortes que caracterizam a Amazônia (PACHECO, 2010).
} 
conforme estabelece as Diretrizes Curriculares para a Educação Escolar Quilombola (DCNEEQ). As comunidades quilombolas possuem um saber peculiar, desenvolvem dinâmicas temporais de vinculação a um espaço físico que se torna território coletivo, resultantes das múltiplas formas de relações integradas à natureza, constituído por conhecimentos gerados e transmitidos pela tradição (BRANDÃO, 2010).

Neste estudo, a configuração da EJA na EEQ é fundamentada em uma memória coletiva que permeia tempos e espaços, e diversos elementos que caracterizem a cultura quilombola, as línguas remanescentes, práticas culturais, produção de trabalho, acervos e repertórios orais. As tradições e demais elementos que configuram o patrimonial cultural das comunidades quilombolas do Brasil, em especial para sua territorialidade. (BRASIL, 2012). Nesse bojo, apontamos a necessidade de dialogar e analisar as interfaces da LI na EJA, na perspectiva da EEQ, saber como os alunos quilombolas marajoaras da EJA constroem seus conhecimentos a partir da relação de cultura, linguagem e sociedade.

A EJA é uma modalidade de ensino que vem se consolidando no Brasil há alguns anos, amparada por lei e voltada para pessoas que não tiveram acesso ao ensino regular na idade apropriada, com foco no processo de alfabetização, reingresso e permanência do aluno nas salas de aulas. Entretanto, esta modalidade de ensino acarreta diversas implicações que impedem sua total eficiência no ensino, como: idade, nível de conhecimento, preconceito, exclusão e estereótipos (grifo nosso) (BRASIL, 2000). Nesse sentido, o ensino da LI nesta modalidade para a EEQ, tem um papel importante na formação interdisciplinar e intelectual dos alunos quilombolas da EJA, quando contribui para a construção da cidadania e da sua própria identidade, favorecendo a participação na sociedade brasileira, sobretudo no mundo globalizado.

A EJA na EEQ da Amazônia Marajoara, apresenta grandes desafios em seu processo de escolarização para os alunos quilombolas. No município de Salvaterra, esse cenário apresenta fortes implicações no aprendizado da LI para os alunos da EJA. Este estudo buscou dialogar sobre o ensino da LI na EJA da Escola Municipal de Ensino Infantil e Fundamental Quilombola Maria Lúcia Ledo Carvalho, da comunidade quilombola de Vila União do município de Salvaterra-Marajó-PA, no sentindo de compreender as diferentes práticas pedagógicas do professor de LI da EJA no âmbito da EEQ, considerando DCNEEQ, Estrutura Curricular Pedagógica da EEQ da Rede Municipal de Salvaterra e as Diretrizes Curriculares Nacionais para a Educação de Jovens e Adultos (DCNEJA).

Desta maneira, apresentamos na primeira seção deste estudo, o percurso metodológico, na segunda seção abordamos o contexto histórico da identidade quilombola marajoara, e em seguida discutimos a concepção da EJA na EEQ, e o contexto da EJA a partir de alunos quilombolas da Amazônia Marajoara. Ao longo do trabalho, discorremos sobre o ensino da LI na EJA e por final apresentamos nossas considerações finais.

\section{PERCURSO METOdOLÓGiCO}

Considerando o objetivo da nossa pesquisa e suas características peculiares, buscou-se a compreensão dos significados produzidos pelos sujeitos: os alunos e professores de LI no contexto social em que atuam. Optamos pela abordagem qualitativa de cunho interpretativista ${ }^{5}$, a qual visa analisar os significados que permeiam o ensino da LI na EJA da EEQ da Amazônia Marajoara.

A abordagem qualitativa é considerada interpretativa e procura descrever os "[...] padrões característicos da vida dos participantes" (MOITA LOPES, 1994, p. 23-24). A abordagem qualitativa busca "[...] a compreensão da realidade humana vivida socialmente" a

\footnotetext{
${ }^{5}$ É também denominada de tradição interpretativista ou hermenêutica-dialética (BORTONI-RICARDO, 2008).
} 
partir dela, trabalha-se com a vivência, a experiência, a compreensão dos resultados da ação humana objetiva, do "[...] ponto de vista onde as práticas e as coisas são inseparáveis" (MINAYO, 1994, p. 23-24).

O paradigma interpretativista pode auxiliar de forma significativa no desenvolvimento de uma compreensão das escolhas e decisões dos participantes em seu tratamento do ensino e aprendizagem em LI. Para Bortoni-Ricardo (2008), esta perspectiva surgiu como uma alternativa para interpretar ações e significados que as pessoas atribuem a tais ações na vida social.

Utilizamos da pesquisa bibliográfica como ponto de partida para mapear a produção intelectual da área e verificamos que a pesquisa qualitativa ajuda na compreensão e interpretações dos fenômenos sociais inseridos no contexto do ensino de LI da EJA na EEQ. Em face disso, podemos reiterar que a pesquisa qualitativa-interpretativista é a mais adequada para este tipo de estudo, uma vez que ela busca descrever o que os sujeitos fazem em seus contextos, e como percebem as suas ações, e como constroem a tecitura do seu mundo social.

O estudo foi realizado na Escola Municipal de Ensino Infantil e Fundamental Quilombola Maria Lúcia Ledo Carvalho, situada na comunidade quilombola de Vila União, com aproximadamente $115 \mathrm{~km}$ de distância do centro urbano da cidade de Salvaterra, MarajóPará. Na pesquisa de campo, foram realizadas algumas visitas ao lócus da pesquisa (Figura 1), a fim de conhecer a realidade escolar e entender o processo socioeducativo dos alunos quilombolas da EJA, além disso foram observadas algumas aulas de LI na EJA, para saber como é trabalhada a cultura quilombola marajoara a partir de seu contexto.

Figura 1 - Escola Municipal de Ensino Infantil e Fundamental Maria Lúcia Ledo Carvalho

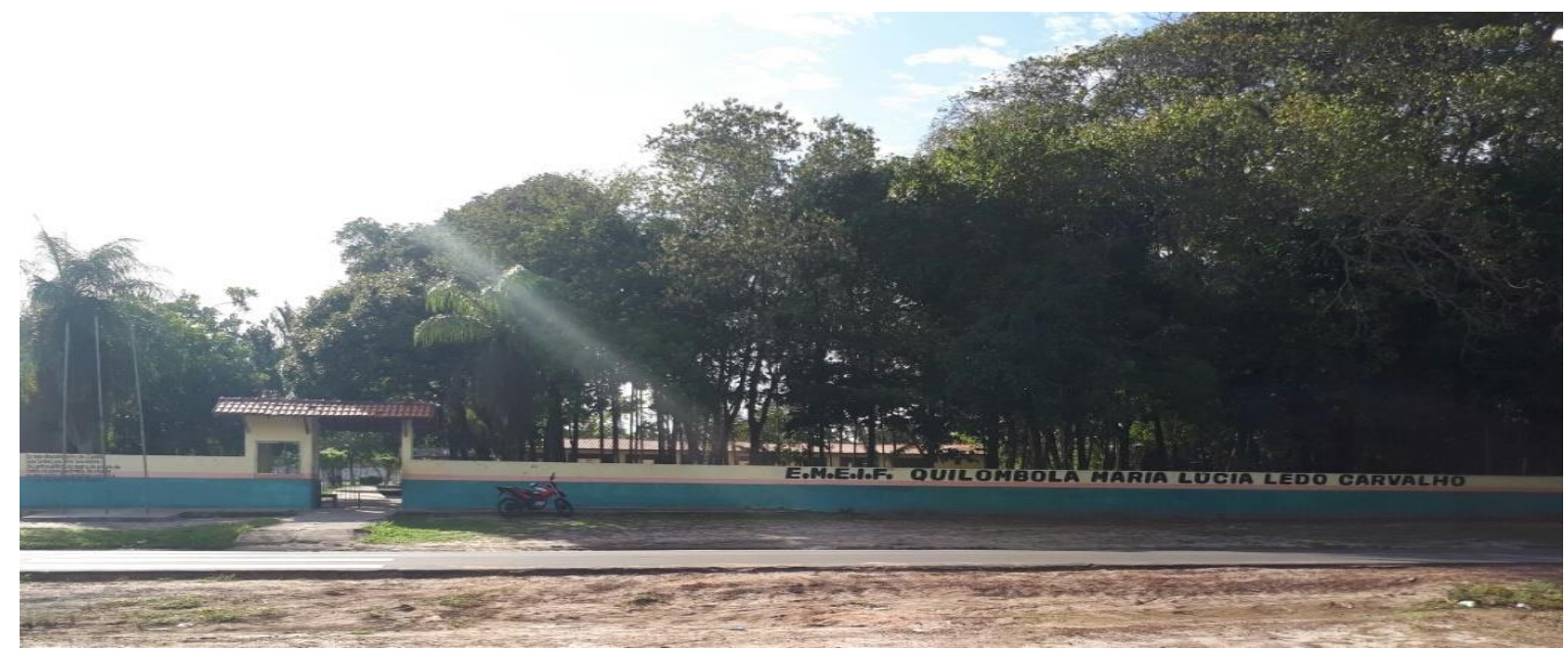

Fonte: Acervo Pessoal dos Pesquisadores, 2020

O Corpus de Análise deste estudo se constituiu na observação e na aplicação de questionário semiestruturado, que foram aplicados com $(=1)$ professora de LI da EJA e com $(=18)$ alunos da $3^{\mathrm{a}}$ Etapa da EJA $\left(6^{\circ}\right.$ e $7^{\circ}$ anos) com um universo de alunos pertencentes a uma faixa etária de 23 a 43 anos de idade, sendo uma turma composta por 11 homens e 7 mulheres. Com o objetivo de analisar as práticas pedagógicas da professora de LI acerca do ensino da LI na EJA da EEQ, os questionários permitiram compreender se as aulas de LI eram articuladas com a proposta da EJA da EEQ na perspectiva das relações étnico-raciais, e perceber como se configura o ensino da LI na EJA da EEQ. Para análise dos dados, consideraram-se as respostas mais expressivas dos alunos e da professora de LI tendo como escopo as representações do ensino da LI na EJA da EEQ, com vista à construção positiva da identidade quilombola marajoara. 
Portanto, foram analisadas e consideradas no questionário, as assertivas mais expressivas, tendo como parâmetro os significados da LI da EJA na EEQ, pela professora de LI e pelos alunos quilombolas. As demais assertivas foram comentadas no decorrer da análise, conforme a relação existente entre o ensino da LI e a EEQ e os seus desdobramentos na EJA.

\section{NAS TRILHAS DOS QUILOMBOS DE SALVATERRA: DA RESISTÊNCIA A SOBREVIVÊNCIA DOS JOVENS QUILOMBOLAS DA AMAZÔNIA MARAJOARA}

A presença de negros e africanos nas regiões brasileiras, estiveram sempre marcadas pela exploração da mão de obra barata e pela vida compulsória nas relações econômicas no período colonial no Brasil. Na Amazônia Marajoara, esse percurso iniciou-se durante o período de criação da Companhia Geral do Comércio do Grão-Pará e do Maranhão em 1755. A presença de negros e africanos na região se intensificou cada vez mais com o aumento da produção agrícola na região Norte e, assim, os negros e africanos foram trazidos compulsoriamente da sua terra natal para a região amazônica (LISBOA, 2012).

Grande parte dessa população formada de negros e africanos, e até indígenas foram direcionadas para a Amazônia Marajoara, com a finalidade de trabalhar nas lavouras, fazendas e criatórios, que gradativamente se organizavam para suas atividades econômicas. A concentração maior dos negros e africanos foi na região do criatório, formada pelas fazendas de gado e búfalos, localizadas nos municípios de Soure, Salvaterra, Cachoeira do Arari, Santa Cruz do Arari e Chaves (LISBOA, 2012).

Ao longo desse período, evidenciou-se uma relação subalterna e compulsória em que os negros e africanos viviam para atender as atividades econômicas impostas pelas autoridades da Coroa Portuguesa. Essa relação estabelecia uma ordem e orientação para que os oficiais acabassem com os antigos mocambos e aldeias (DIAS, 2016).

Quanto à questão subalterna e compulsória de negros e africanos nessa porção da região da Amazônia Marajoara, Baena (2004) considera que haviam 31 negros e africanos em Salvaterra na década de 1830. O autor também apresenta dados historiográficos do século XVIII que estão vinculados à atual formação de territórios quilombolas nessa região.

\footnotetext{
Baena descreve a "roça São Macário", no século XVIII, “aderente” à fazenda São Lourenço ou Paracauari que pertenceu aos padres mercedários e, no ano de 1794, foi-lhes sequestrada. Essa informação é um elo importante dos povoados negros de Salvaterra, pois nas terras dessa ordem surgem as terras de Santa Mercês, ocupadas pelos “pretos velhos" de Bacabal, do Bairro Alto. (ACEVEDO, 2009, p. 214).
}

Nesse interim, Salvaterra é considerada a cidade da Amazônia Marajoara que apresenta maior número de comunidades quilombolas. De acordo com os dados da Fundação Cultural dos Palmares (FCP), o município de Salvaterra apresenta 17 comunidades quilombolas: Bacabal, Santa Luzia, Rosário, Campina, Vila União, Valentim, Boa Vista, Deus Ajude, Bairro Alto, Caldeirão, Pau Furado, São Benedito Salvá, Mangueiras, Providencia, Siricarí.

Segundo Arruti (2017), o conceito de quilombo é amplo e complexo, e permeia por discussões referentes ao uso comum da terra e da identidade étnica das populações quilombolas. Nesse sentido, o conceito de quilombo neste estudo remete à variação de identidade quilombola, ancestralidade, a vinculação com a terra ligada a coletividade do grupo social. Para Almeida (2005), esse sentido possui uma relação com áreas doadas, repassadas ou conquistadas por um grupo ou uma pessoa de origem negra que possua documentação legalizada.

Esse percurso referente à definição de quilombo foi o que demarcou os territórios das comunidades quilombolas de Salvaterra, e caracterizou a identidade quilombola marajoara 
como coletiva e legítima, associada pelo vínculo com a terra, modo de vida, produção e cultura. Essa relação buscou ampliar as políticas públicas de ações afirmativas, como saúde e educação. Segundo Acevedo (2009), o município é eminentemente quilombola:

\begin{abstract}
Quilombolas de Salvaterra produziram um processo de territorialização que experimenta mudanças devido à existência de condições limitantes à sua existência, aos modos de produzir e de organizar a vida social. As cercas construídas pelos fazendeiros, cujo primeiro significado é de identificação e de relação com um "dono, proprietário", privatizam os recursos (igarapés, lagos) e estabelecem impedimento, coerção, restrição de deslocamentos, de gozo da liberdade de movimentar-se livremente no território. (ACEVEDO, 2009, p. 215).
\end{abstract}

Segundo os dados do Centro de Estudos e Defesa do Negro no Pará (CEDENPA), Instituto de Colonização e Reforma Agrária (INCRA), Instituto de Terras do Pará (INTERPA) e Coordenação das Associações Remanescentes de Quilombo do Pará (MALUNGU), as comunidades quilombolas de Salvaterra começaram a requerer a titulação e certificação de suas terras desde 2000. O município de Salvaterra é eminentemente quilombola, e suas comunidades estão concentradas no espaço rural, e foi a partir de 2004 que as comunidades começaram a ser certificadas perante aos Órgãos Competentes.

A partir de vários movimentos de reivindicações para o reconhecimento de suas terras, foram que as comunidades quilombolas de Salvaterra começaram a se organizar e se estruturar de maneira mais sólida. Doravante, as comunidades começaram a lutar por seus direitos, dentre eles o de construir uma sociedade que respeitasse sua identidade e cultura, surge então, o sentimento de construção de escolas nas comunidades quilombolas de Salvaterra.

A EEQ foi implantada no município de Salvaterra em 2013, através do Parecer $\mathrm{n}^{\circ}$ 392/13 e a Resolução no 418/213, emitido pelo Conselho Estadual de Educação do Estado do Pará (CEE/PA), com a implementação das Estruturas Curriculares para a EEQ do Ensino Fundamental no município de Salvaterra. A necessidade de implantar a EEQ no município surgiu a partir das reivindicações das lideranças das comunidades quilombolas de Salvaterra, que ora foram representados pelo Movimento Quilombola de Salvaterra (MQS), que lutaram pela construção e/ou readaptação de escolas em Comunidades Remanescentes Quilombolas (CQR), e que atendessem as peculiaridades da população quilombola marajoara, reafirmando o compromisso e implementação da Lei no 10.639/2003.

A EEQ possui um contexto histórico de institucionalização sob a conquista do Movimento Negro e Quilombola no Brasil, que possibilitou o acesso ao ensino básico da população negra, como reconhecimento do direito à educação. Uma luta que foi enfrentada e conquistada como proposta desde o processo de implementação da Lei $\mathrm{n}^{\circ}$. 10.639/03, sendo referenciada no Plano Nacional de Implementação das Diretrizes Curriculares Nacionais para a Educação das Relações Étnico-raciais e para o Ensino de História e Cultura Afro-brasileira e Africana.

Diante de um panorama de reivindicações do Movimento Negro e Quilombola acerca do direito a educação, diversas discussões e atividades foram organizadas pelo Grupo de Trabalho para Educação Quilombola, junto ao Conselho Nacional de Educação (CNE). Nesse sentido, no ano de 2012, as DCNEEQ's, foram elaboradas e aprovadas pela Câmara de Educação Básica do Conselho Nacional de Educação. Dessa forma, o ensino é destinado às populações quilombolas como política pública educacional é concebida como:

Art. 9: A Educação Escolar Quilombola compreende:

I - escolas quilombolas

II - escolas que atendem estudantes oriundos de territórios quilombolas. 
Parágrafo Único: Entende-se por escola quilombola aquela localizada em território quilombola. (BRASIL, 2012, p. 18).

Ao compreender que a EEQ concebe o território como uma categoria principal na modalidade de ensino, esta define como essa política pública educacional deve ser adotada na educação básica. Nesse sentido, a definição de quilombo no Brasil, transita por diferentes momentos e processos históricos de ancestralidade das populações negras no país, buscando não recair sobre uma conotação que naturaliza esse termo somente ao processo de exploração dos negros em séculos passados.

De acordo com a DCNEEQ, a EJA é uma modalidade legalmente amparada na EEQ, com uma proposta pedagógica flexível, com finalidades e funções específicas, levando em consideração os conhecimentos das experiências de vida dos jovens e adultos quilombolas, atendendo às realidades socioculturais e interesses das comunidades quilombolas. A proposta pedagógica deve ser contextualizada, levando em consideração seus tempos e espaços, às suas questões históricas, sociais, políticas, culturais e econômicas das comunidades quilombolas (BRASIL, 2012).

As DCNEEQ's, no art. no. 23 preconizam que a oferta da EJA no Ensino Fundamental da EEQ, deva substituir a oferta regular dessa etapa da Educação Básica na EEQ, independentemente da idade:

$\S 4^{\circ} \mathrm{Na}$ Educação Escolar Quilombola, as propostas educativas de EJA, numa perspectiva de formação ampla, devem favorecer o desenvolvimento de uma Educação Profissional que possibilite aos jovens, adultos e idosos quilombolas atuar nas atividades socioeconômicas e culturais de suas comunidades com vistas ao fortalecimento do protagonismo quilombola e da sustentabilidade de seus territórios. (BRASIL, 2012, p. 11).

A EJA na EEQ, portanto, vai além dos sujeitos tradicionalmente compreendidos como adultos e fora da escola, estabelecendo diferentes conexões e trajetórias daquela que, por algum motivo, foi estabelecida e considerada como "padrão" ou norma na sociedade, trazendo em seu escopo, também, grupos sociais que possuem cultura e produção de conhecimentos peculiares, como indígenas, ribeirinhos, camponeses, imigrantes entre outros. De uma forma ou de outra, a EJA da EEQ se configura com identidades que são socialmente ignoradas, silenciadas e invisibilizadas, tidas como irregulares indesejáveis e fora do padrão, que sofrem tentativas de "normalização" (SKLIAR, 2006, p. 23), e apagamento quando silenciam suas características peculiares em prol de um padrão assumido como único.

\section{EDUCAÇÃO DE JOVENS E ADULTOS E A EDUCAÇÃo ESCOLAR QUILOMBOLA}

A EJA passou a ser reconhecida em vários países devido às conferências organizadas pela a Organização das Nações Unidas para a Educação, Ciência e Cultura (UNESCO) nos anos 1940. A partir de então, surgiu no Brasil um movimento de mobilização nacional, no sentido de diagnosticar metas e ações para a EJA (SCHNEIDER; FONSECA, 2013). Contudo, a educação formal e escolar de jovens e adultos só começou a ter condições reais de existência e execução como política pública a partir de 1990 (HADDAD; DI PIERRO, 2000), sendo solidificada e reconhecida como modalidade com a criação da Lei de Diretrizes e Bases da Educação (LDB nº. 9.394/96).

A Constituição Federal Brasileira de 1988, declarou a obrigatoriedade e o acesso à educação a toda a população brasileira. Nesse sentido, 
[...] educação é direito de todos e dever do Estado e da família, será promovida e incentivada com a colaboração da sociedade, visando ao pleno desenvolvimento da pessoa, seu preparo para o exercício da cidadania e sua qualificação para o trabalho. (BRASIL, 1988, p. 63).

Dessa maneira, todos os cidadãos brasileiros têm direito a educação pública, independentemente de suas desigualdades sociais. O Estado é obrigado a ofertar e ampliar vagas para todos os níveis da educação básica, incluindo a EJA (BRASIL, 2000). A LDB nº. 9.394/96 é o documento basilar que ampara legalmente as diretrizes para a EJA na educação brasileira. Nesse sentido, o art. $n^{\circ} .37$, da Lei $n^{\circ} .9 .394 / 96$, considera que "A educação de jovens e adultos será destinada àqueles que não tiveram acesso ou continuidade de estudos no ensino fundamental e médio na idade própria" (BRASIL, 1996)

Destarte, Arroyo (2011), adensa que para atender os processos socioeducativos a EJA não se pode tomar apenas os documentos oficiais e as políticas públicas que abalizam e orientam essa modalidade de ensino, mas compreender como os sujeitos se constituem e se organizam:

\footnotetext{
A Educação de Jovens e Adultos tem de partir, para sua configuração como um campo específico, da especificidade dos sujeitos concretos, históricos que vivenciam esses tempos da vida - juventude e vida adulta - e da especificidade dos sujeitos concretos históricos que vivenciam esses tempos. (ARROYO, 2011, p. 22).
}

A EJA possui uma longa trajetória no Brasil, galgada de lutas e enfrentamos em face das grandes desigualdades sociais que assolam a sociedade brasileira. "[...] a história da EJA transitou à margem da construção do Sistema Escolar: campanhas, movimentos sociais, Organizações Não Governamentais - ONG's, Igrejas, Sindicatos e Voluntários" (ARROYO, 2011, p. 43). No âmbito das políticas públicas, a EJA passou por diversas transições e tensões, até chegarmos aos dias atuais. Arroyo (2011, p. 19) já asseverava que este é “[...] um campo ainda não consolidado nas áreas de pesquisa, políticas públicas e diretrizes educacionais, da formação de educadores e intervenções pedagógicas".

É preciso considerar neste estudo que os alunos quilombolas marajoaras da EJA, especificamente das escolas quilombolas de Salvaterra, possuem vivências, experiências e conhecimentos que os diferem dos alunos da educação regular. Entretanto, é indispensável descortinar os olhos e focar nos desafios existentes quando se almeja uma educação de qualidade no âmbito da Amazônia Marajoara. Sendo necessário proporcionar reflexões sobre os desafios da EJA na EEQ no campo do ensino da LI, a fim de que possam avançar gradualmente no mundo do conhecimento e do trabalho, respeitando suas especificidades, onde a escola e os professores passem a refletir ainda mais sobre o ensino da LI para estes alunos tanto na vida escolar quanto na vida social.

A EJA atende principalmente a população mais carente da sociedade brasileira, que se viu durante muito tempo excluída do processo educacional por múltiplas causas. Diante de uma realidade marcada por desigualdades sociais (BRASIL, 2000), as questões étnico-raciais e a EJA, nunca andaram separadas, percebemos que os negros sempre estiveram presentes nessa modalidade de ensino, especialmente por fazer parte das populações subalternas, silenciadas e negligenciadas, neste caso das comunidades quilombolas que por várias vezes foram excluídas do processo educacional.

Pensar a realidade da EJA é pensar a realidade dessas pessoas excluídas e marginalizadas pela sociedade e pela educação, pois desde quando a EJA se constituiu, os alunos jovens e adultos sempre foram considerados pobres, desempregados e excluídos (ARROYO, 2011). Os métodos de combate às desigualdades sociais na EJA devem ter lugar priorizado nos seus processos educativos, principalmente sob o olhar dos profissionais da 
educação, visto que o preconceito e discriminação difundidos de maneira (in)consciente, são entendidos como uma barbárie, caracterizando uma violência simbólica, e que por sua vez deve ser combatido com uma intervenção pedagógica.

A presença de alunos quilombolas nas salas de aula nessa modalidade de ensino, não tem sido suficiente para a garantia e realização de um trabalho pedagógico de qualidade. Ensinar na EJA da EEQ exige a aceitação do novo e o abandono de qualquer forma de preconceito e discriminação. O ensino da LI nessa modalidade de ensino é considerado um sistema muito complexo, por entender que a fase da vida dos alunos exige da EJA demandas educativas específicas, características diferentes de aprendizado, práticas adequadas de trabalho e representações distintas acerca da idade escolar.

O professor de LI da EJA na EEQ deve (des)construir seus conceitos e pensamentos no seu cotidiano escolar, considerando as pluralidades de seu alunado. Diante disso, o educador de LI da EJA deve oferecer um ensino que valorize os saberes, as tradições e o patrimônio cultural das comunidades quilombolas e fortalecer a implementação da Lei $\mathrm{n}^{\mathbf{o}}$ 10.639/2003 sobre o ensino das relações étnico-raciais na educação brasileira.

Além dos aspectos apontados até aqui, a relação de ensinar e aprender a LI na EJA perpassa o reconhecimento de múltiplos saberes e a relação dialógica de Freire entre "educador-educando" e "educando-educador" que trazem saberes diversos para dialogar (FREIRE, 1987, p. 46) e aprender um com o outro. Na próxima seção discorreremos sobre o contexto em que se insere a EJA da Amazônia Marajoara, sob as luzes da EEQ.

\section{O ENSINO DA LÍNGUA INGLESA NA PERSPECTIVA DA EDUCAÇÃO ESCOLAR QUILOMBOLA EM SALVATERRA-PA}

Diante das reflexões apresentadas até aqui, é emergente e relevante compreender como as práticas pedagógicas para o ensino da LI no âmbito da EJA da EEQ são desenvolvidas nas comunidades quilombolas da Amazônia Marajoara. De acordo com as DCNEEQ, a proposta da LI na EJA da EEQ deve ser de natureza interdisciplinar, envolvendo os saberes tradicionais das comunidades quilombolas. Esses saberes devem valorizar identidade, ancestralidade, memória, religiosidade e os saberes culturais a partir de uma matriz africana para que, assim, o ensino da LI atinja as perspectivas interculturais no âmbito da EEQ. O processo de ensino aprendizagem em LI devem contemplar conteúdos que levem a refletir a realidade local quilombola, de modo em que os alunos quilombolas os internalizem criticamente a partir da sua realidade social, imbuído de fortalecer sua própria identidade.

É importante compreendermos que o contexto histórico da Língua Estrangeira (LE) na educação brasileira sofreu uma perda gradativa para o ensino da LI na educação básica, na qual houve pouca regulamentação curricular, e que ocasionou uma série de desafios para o ensino do idioma no Brasil e, consequentemente, esses desdobramentos inviabilizaram a qualidade do ensino da LI na escola pública. Todavia, em 2017, através da Lei $\mathrm{n}^{\circ}$ 13.415/2017, a LI tornou-se a LE obrigatória a partir do $6^{\circ}$ ano do Ensino Fundamental.

Doravante, em 2018 foi homologada a Base Nacional Curricular Comum (BNCC) para o Ensino Fundamental, um documento de natureza normativa com parâmetros e diretrizes para a educação brasileira, e a partir de 2020 esse novo documento curricular passou a ser implementado na educação básica. No âmbito da LI, a BNCC prescreve em suas diretrizes um ensino galgado na globalização, possibilitando ao aluno o acesso aos saberes linguísticos necessários para o seu desenvolvimento crítico e intelectual. $\mathrm{O}$ documento considera a LI como língua franca, e é concebida como multiletramento, possibilitando o aluno de circular e interagir em diferentes semioses e linguagens verbais, desenvolvendo a competência comunicativa em LI por meio do seu engajamento discursivo (BRASIL, 2017). 
De acordo com os documentos curriculares legais da educação brasileira, o ensino da LI deve priorizar um aprendizado em multiletramentos e competências comunicativas. No município de Salvaterra, os documentos curriculares que abalizam a EEQ no âmbito do ensino da LI, tem uma proposta curricular dividida em quatro eixos em sua redação, e que devem ser aplicados, articulados e trabalhados a todos os conteúdos dos diversos componentes curriculares elencados na matriz curricular, são eles: Memória e Cultura; Saberes e Tecnologia; Relações Ambientais; Promoção e Igualdade Racial e de Gênero. (SALVATERRA, 2017). O documento orienta ainda que os conteúdos devem contemplar a amplitude da diversidade cultural das comunidades quilombolas e da sociedade afrobrasileira.

Nesse sentido, o documento apresenta uma perspectiva de trabalho galgada no caráter interdisciplinar, no qual constitui o campo de estudos teóricos dessa proposta curricular. Para isso, discute aspectos não somente culturais, mas políticos, econômicos, geográficos, pedagógicos e éticos, como conteúdos inseridos à pluralidade cultural, necessários para a construção de uma identidade nacional.

O documento orienta também a seleção dos conteúdos que devem ser articulados na proposta da EEQ, buscando contemplar a amplitude da diversidade cultural das comunidades quilombolas e da sociedade afro-brasileira. Segundo o documento, o ensino da LI faz parte juntamente com os conteúdos de Português e Literatura:

1- Textos Leituras, interpretação e produções diversas; concursos de frases, poesias, músicas, paródias;

1.1 Contadores de histórias locais (narrativas, contos e causos);

1.2 Provérbios populares;

1.3 Poetas, poesias, e contos, causos e lendas;

1.4 Falares africanos x língua colonizadora;

1.5 Os países e os idiomas falados por eles;

1.6 As influências estrangeiras.

(SALVATERRA, 2017, p. 3).

De acordo com a proposta do ensino da LI na EEQ, a ideia apresentada descortina a imagem que temos sobre o ensino da LI difundida na educação básica, sobre imperialismo linguístico cultural estadunidense e/ou britânico no currículo escolar, uma vez que o ensino da LI sustenta um processo de expansão ideológica e de dominação e hegemonia no mundo. Rajagopalan (2003, p. 17) considera que "o ensino de língua de maneira bem geral, em especial de línguas estrangeiras, faz parte de uma política linguística em vigor num determinado país", devendo o ensino da LI ir para além do que preconiza os estudos linguísticos, sucumbindo aspectos sociopolíticos e coordenadas geográficas, nas quais influenciam indiretamente o comportamento linguístico do cidadão quanto políticas públicas adotadas por seus Governos.

Nesse sentido, evidencia-se o panorama histórico e hegemônico do ensino da LI, descortinando seus mecanismos de legitimação e descentralização das culturas consideradas hegemônicas nas de aulas LI (cultura britânica e estadunidense), rompendo com os paradigmas tradicionais legitimados no currículo escolar. Essa ruptura, abre caminhos para uma perspectiva intercultural no ensino da LI, na qual valorize a diversidade cultural deste idioma, reconhecendo a heterogeneidade e outras interfaces do uso da LI de outros países anglófonos, nesse caso de afro-anglófonos para o ensino da LI na EEQ.

Dentro do contexto e da configuração da EEQ, o ensino da LI deve apresentar interfaces que contemplem uma matriz africana e que possibilite (re)pensar uma prática pedagógica de ensino antirracista e inclusiva. O professor de LI da EJA da EEQ deve pensar em uma perspectiva de ensino intercultural, que busque questionar o modelo político vigente 
neoliberal, de modo a favorecer a coesão social dos grupos quilombolas historicamente (in)visibilizados e silenciados.

A LI como instrumento de prática social, é abordada pelo seu histórico hegemônico, sobreposta na cultura branca (britânica e estadunidense), é um instrumento ideológico nas relações de poder no mundo globalizado. Dessa forma, o ensino da LI na EJA da EEQ deve descortinar e incorporar outros planos da diversidade cultural apresentado pelo idioma, a partir da cultura afro-anglófona ${ }^{6}$.

Dessa forma, o ensino da LI na EJA da EEQ tem um papel de descortinar o cânone da supremacia das culturas hegemônicas anglófonas (britânicas e estadunidenses), diluídas e legitimadas no currículo e nas práticas pedagógicas dos professores de LI. Para isso, realizamos na próxima seção um recorte para compreendermos como a LI é trabalhada e articulada na EJA da EEQ em Salvaterra, sobretudo nos desdobramentos da identidade quilombola marajoara dos alunos EJA em seu ambiente escolar.

\section{O ENSINO DA LÍNGUA INGLESA NA PERSPECTIVA DA EDUCAÇÃO ESCOLAR QUILOMBOLA: DESAFIOS DE UMA PROFESSORA DE LÍNGUA INGLESA E DE ALUNOS QUILOMBOLAS MARAJOARAS NA EDUCAÇÃO DE JOVENS E ADULTOS}

Aqui iniciamos um recorte analítico do ensino da LI na EJA na perspectiva da EEQ em Salvaterra, no sentido de compreender como a LI é trabalhada e articulada com os saberes tradicionais dos alunos quilombolas marajoaras. Buscamos evidenciar, por meio de questionários direcionados a professora de LI e aos alunos quilombolas da EJA, como é trabalhada a cultura quilombola marajoara e afro-brasileira nas aulas de LI. Ademais, foi evidenciado como a identidade dos alunos quilombolas marajoaras sofrem influências e os resquícios hegemônicos de culturas esbranquiçadas para o ensino da LI na EJA da EEQ de Salvaterra.

Durante a pesquisa de campo, percebemos que as propostas pedagógicas da professora de LI na sala de aula da EJA na EEQ se assemelham a uma perspectiva de ensino urbanocêntrico, onde os alunos quilombolas da EJA ainda estão (in)visibilizados quanto a valorização dos seus saberes culturais nas aulas de LI. A perspectiva de ensino da professora de LI ainda apresenta resquícios coloniais de cultura esbranquiçada e hegemônica, dificultando um ensino adensado na matriz africana e afro-brasileira.

De acordo com as entrevistas realizadas com a professora de LI, ela apontou que seu maior desafio para ensino de LI na EJA da EEQ, seria a falta de formação continuada para as relações étnico-raciais. Para ela, a capacitação nas relações étnico-raciais seria o ponto de partida para compreender melhor o processo de ensino aprendizagem da LI na EJA da EEQ. Nesse sentido, foi questionado à professora como ela busca trabalhar os elementos da cultura quilombola marajoara ou afro-brasileiras em suas aulas, e ela considerou:

Eu sinto dificuldades em trabalhar elementos da cultura quilombola marajoara nas aulas de inglês, na minha formação acadêmica não tive nenhuma formação para as relações étnico-raciais, sempre aprendemos o inglês na perspectiva americana $e$ britânica, para assim ensinar aos nossos alunos. (PROFESSORA DE LÍNGUA INGLESA.)

A partir do enunciado da professora, podemos perceber o quanto que a hegemonia e supremacia cultural da LI presente em suas práticas pedagógicas atravessam tempos e espaços

\footnotetext{
${ }^{6}$ Territórios e nações que têm o inglês como língua materna no continente Africano. Seus principais núcleos encontram-se: África do Sul, Gâmbia, Libéria, Serra Leoa, Zâmbia, Zimbábue.
} 
na educação brasileira, e que estão fortemente influenciadas nas formações acadêmicas alinhadas a um currículo eurocêntrico e norte americano. $O$ inglês difundido na educação brasileira ainda possui resquícios de uma matriz curricular embranquecida (britânica e estadunidense), constituindo uma supremacia linguística e hegemônica, que naturaliza o ensino numa perspectiva colonial. Nesse sentido, podemos evidenciar o campo complexo e desafiador para o ensino da LI para alunos da EJA na EEQ, e (re)pensar a necessidade emergencial para uma concepção de aprendizagem que compreenda a língua como cultura viva na EEQ. Sobre isso, Rajagopalan (2003) adensa que há uma necessidade de compreender $o$ processo de aprendizagem em língua estrangeira como parte integrante do processo (re)definição de identidade cultural do aluno(a).

Considerando esse panorama complexo e desafiador do ensino de LI para alunos da EJA na EEQ, questionamos da professora de LI como ela trabalha para manter os alunos motivados nas suas aulas, no sentido de evitar a evasão escolar:

\begin{abstract}
$E ́$ um desafio extremamente grande e complexo em trabalhar com alunos da EJA da $E E Q$, em virtude que muitos deles possuem famílias e atividades de subsistência, tendo que muitas das vezes se ausentarem da escola para cuidar de suas atividades na agricultura e na pesca. Eu sempre procuro entender essa realidade e ajudar na medida do possível, garantindo aos alunos que no retorno de suas atividades façam suas atividades pendentes, e procuro relacionar suas histórias de vida nas aulas de LI a partir de história de povos afro-anglófonos que sofreram durante muito tempo em busca de melhores condições de vida. (PROFESSORA DE LÍNGUA INGLESA).
\end{abstract}

Diante do relato da professora, podemos perceber que os desafios no ensino da LI passam a ser o fio condutor em suas aulas, levando-a a questionar e repensar seus métodos de ensino e abordagens como elementos neutros e absolutos, descobrindo seus horizontes por uma busca de novas epistemologias e por uma visão mais crítica da produção do conhecimento. Essa visão, levou a professora a compreender a necessidade de um olhar mais sensível e (de)colonial no ensino da LI da EJA, voltado a conhecer melhor os seus estudantes, e ao mesmo tempo buscar pedagogias mais sensíveis às suas necessidades e realidades, isso evidencia uma relação dialógica e horizontal em que o professor quanto alunos aprendem simultaneamente (MIGNOLO, 2014; KUMARAVADIVELU, 2016).

Com base nas questões apresentadas pela professora, é importante compreendermos a ideia de (de)colonialidade empregada neste estudo. Para discutir esse conceito, recorremos a Mignolo (2014, p. 105), que entende como um "movimento de resistência teórico e prática, político e epistemológico, à lógica da modernidade/colonialidade". Por isso, a perspectiva (de)colonial propõe uma ação de enfrentamento à visão colonial, ela permite desenvolver um pensamento crítico por outras visões, e que possam apontar para nossas regionalidades e tradições, como enfrentamento ao pensamento colonial eurocêntrico.

As perspectivas adotadas pela professora de LI, corroboraram para a desconstrução da imagem hegemônica e cultural do ensino da LI na educação brasileira, e permitiu visibilizar outros protagonismos para o ensino do idioma. As culturas afro-anglófonas foram cânones para a desconstrução e reconstrução das abordagens culturais difundidas no ensino da LI na EEQ, e serviu para validar e fortalecer a implementação da Lei. $n^{\circ} 10.639 / 03$ nas aulas de LI, sobretudo a EEQ.

Logo, é de fundamental importância legitimar as contribuições políticas, culturais, sociais e linguísticas dos povos afro-brasileiro, para a formação socioeducativa dos alunos quilombolas da EJA, sobretudo no âmbito do ensino da LI a partir das contribuições culturais de povos afro-anglófonos. Dessa forma, o trabalho do professor de LI da EJA na EEQ, deve voltar-se para a importância da implementação Lei $\mathrm{n}^{\circ} 10.639 / 03$ e de uma proposta pedagógica interdisciplinar, comprometida em (re)conhecer seus princípios norteadores e 
relacioná-los a sua prática pedagógica, voltando-se contra a perpetuação das desigualdades sociais, como também o imperialismo linguístico padronizado (estadunidense e britânico) para o ensino da LI difundido no currículo e nas práticas pedagógicas dos professores de LI da educação brasileira.

No questionário aplicado aos alunos da EJA da EEQ, evidenciamos uma turma bastante heterogênea e com grandes pluralidades. Diante dessa realidade, percebemos que a LI é considerada uma disciplina bastante complexa para os alunos. A falta de conhecimentos linguísticos em sua língua materna dificulta o aprendizado da LI. Nesse sentido, foi questionado a eles se as aulas de inglês eram relacionadas com a cultura quilombola marajoara ou afro-brasileira. De acordo com os enunciados dos alunos, eles consideraram:

Nossas aulas de inglês são bem divertidas e legais, a professora as vezes trabalha a cultura africana nas aulas por meio da história de personagens negros brasileiros, mas eu não consigo entender muito essa relação. (ALUNO DA EJA, 22 ANOS DE IDADE).

Uma vez a professora trabalhou os nomes das frutas locais da nossa comunidade em inglês, eu achei interessante porque nós conseguimos aprender o nome dos nossos alimentos em inglês, eu até ensinei para meus familiares. (ALUNA DA EJA, 38 ANOS DE IDADE).

Eu não consigo aprender inglês e nunca vi nenhuma pessoa da minha comunidade falar o inglês bem, na verdade eu nunca vi uma pessoa negra falar inglês igual os turistas estrangeiros que vem visitar Salvaterra. Eu acho difícil, a professora tenta nos ajudar, mas é muito difícil. (ALUNO DA EJA, 24 ANOS DE IDADE).

Diante dos relatos apresentados pelos alunos, é possível evidenciar de forma triangular a relação dos ideais de "raça branca" à concepção e valorização cultural da LI difundida na escola pública, consubstanciada no ensino da cultura hegemônica e embraquecida, na qual o professor apropria-se da cultura de determinado país (geralmente Estados Unidos ou Inglaterra) para o ensino da língua estrangeira (MOITA LOPES, 2005, grifo nosso). Nesse sentido, a professora de LI da EJA da EEQ, acaba (re)produzindo estereótipos e noções de verdade que valorizam culturas hegemonias em detrimento à cultura dos alunos quilombolas, principalmente quando o ensino da LI é abalizado na cultura estadunidense e/ou americana.

Nesse sentido, é possível evidenciar as influências hegemônicas e coloniais que a escola tem em relação à identidade dos alunos quilombolas marajoaras, e a própria professora de LI da EJA da EEQ. Nesse sentindo, Pennycook (1998), Moita Lopes (2002) Ferreira (2006) asseveram que o papel do professor tem função maior de educar cidadãos, formar sujeitos conscientes e críticos para que esses vivam e interajam na sociedade com uma postura de questionamentos, rupturas e resistência.

O ensino da LI tem desdobramentos agravantes na EEQ, com a valorização do ensino de matriz embranquecida e hegemônica (estadunidense e britânica). Essa cosmovisão é perceptível quando analisamos por exemplos os livros didáticos de inglês, e por evidenciar uma corrente positiva e tendenciosa pela supremacia cultural e hegemônica da LI. Desse modo, o professor de LI, ainda possui uma visão holística pela língua perfeita e colonial, exigindo do aluno o uso da língua "correta" que contemple padrões linguísticos culturais hegemônicos (britânico e estadunidense). Para Apple (2002) e Pennycook (1998), essa relação traduz a ideia de poder-ensino que configura a escola contemporânea, quer seja brasileira ou estrangeira, instituindo a educação como uma relação de poder na sociedade.

Ao se pensar na formação de professores nas universidades, existe uma relação que excede as paredes da academia. O reconhecimento do "poder" existente no engajamento discursivo do professor influencia diretamente e inconscientemente a relação professor/aluno 
para além das salas de aulas. O professor perante os seus alunos, são submetidos a um discurso, e à uma relação de poder, em virtude que maioria dos alunos desconhecem determinados temas e pensamentos, acreditam geralmente naquilo que é difundido pelo professor (MOITA LOPES, 2002; PENNYCOOK, 1998; APPLE, 2002, grifo nosso)

A partir desses apontamentos, foi questionado à professora se durante a graduação ela havia participado e/ou recebido formação acadêmica de algum curso sobre EEQ? Ela considerou: "Não, na universidade nós nunca tivemos nenhuma disciplina que pudesse trabalhar a educação quilombola e nem mesmo as relações étnico-raciais, eu até desconhecia a Lei 10.639/03 antes de trabalhar na escola quilombola". Podemos observar no relato da professora, a falta de formações e discussão na academia voltada para as relações étnico-raciais, e esse panorama inviabiliza atender a proposta da EEQ, sobretudo para o ensino da LI. Segundo a professora, suas práticas pedagógicas buscam correlacionar os elementos da cultura quilombola marajoara e afro-brasileira em suas aulas, utilizando textos e vocabulários do cotidiano da comunidade, sendo que os textos geralmente são de sua autoria e que sempre buscaram trazer para dentro de sala de aula os saberes da comunidade quilombola de Vila União.

Para isso, precisamos romper com a ideia de ensino tradicional da LI, ancorado e difundido por princípios coloniais, homogêneos, esbranquiçados e elitizados. Temos que romper com o ensino as desigualdades sociais, para assim atendermos a proposta da EEQ, sobretudo no âmbito da EJA. Pennycook (1998) e Silva (2009), apontam que romper com o ensino tradicional não é uma tarefa fácil, pois as concepções de mundo no fazer docente precisam ser reavaliadas às novas concepções que propõem reflexões e estudos, de maneira a ressignificar novas concepções e que façam mais sentidos para novas propostas e práticas pedagógicas.

\section{CONSIDERAÇÕES FINAIS}

A EJA na história na educação brasileira é marcada por profundas desigualdades sociais, políticas e econômicas. Na EEQ, essa modalidade apresenta grandes desafios para o ensino da LI, por entender um conjunto complexo de epistemologias que visam articular saberes das comunidades tradicionais, afro-brasileiras às práticas pedagógicas do professor de LI.

Este estudo permitiu compreender e refletir sobre os desdobramentos da LI na identidade quilombola marajoara para os alunos da EJA. A partir do referencial teórico, foi possível descortinar novos olhares para o ensino da LI na EJA da EEQ. Nesse bojo, percebemos que os alunos da EJA internalizam o aprendizado da LI a partir de uma ideia ainda fragmentada. Essa inflexão evidenciou a impetuosa supremacia da LI difundida a partir de culturas hegemônicas e brancas (estadunidense e britânica) nas práticas pedagógicas dos professores de LI da educação básica da EEQ.

Percebemos que o maior desafio do professor de LI é trabalhar as relações étnicoraciais e validar a Lei $\mathrm{n}^{\mathrm{o}}$. 10.639/03 nas aulas de LI da EJA na EEQ. A partir dos resultados, foi possível perceber que um dos maiores desafios existentes para o ensino de LI na EJA está na carência de formação continuada para professores que atuam nessa modalidade de ensino. A falta de apoio pedagógico e materiais didáticos voltados para as especificidades dos alunos quilombolas têm sucumbindo a qualidade do aprendizado em LI para alunos da EJA na Amazônia Marajoara.

Mesmo com todos os desafios evidenciados até aqui, ainda assim, a LI tem um papel importante para esses alunos e também para a comunidade Quilombola de Vila União. Através da LI, os alunos poderão tomar conhecimento sobre outras culturas e a sua própria 
cultura quilombola a partir de outros protagonismos negros, que levem em consideração as culturas afro-anglófonas para o aprendizado do idioma.

O ensino da LI na EJA da EEQ da Amazônia Marajoara, precisa inserir em seu horizonte, a necessidade de ensinar inglês de uma maneira interdisciplinar e contextualizada, no âmbito das especificidades locais da cultura quilombola marajoara. Dada a importância do tema, torna-se necessário aprofundar mais estudos do ensino da LI na EJA da EEQ, pois é perceptível que o desafio maior está na forma como a LI é ensinada e difundida nessa modalidade de ensino, e também na capacitação de professores de LI para desenvolverem competências necessárias para contemplar a proposta da EJA na EEQ.

\section{REFERÊNCIAS}

ACEVEDO, Rosa Elizabeth. Quilombolas na ilha do Marajó: Território e organização política. In: GODOI, Emília Pietravesa; MENEZES, Marilda Aparecida de. Diversidade do campesinato: expressões e categorias: construções identitárias e sociabilidades. v 1. São Paulo: Editora UNESP, 2009.

ALMEIDA, Maria Geralda. Fronteiras, Territórios e identidades. Revista ANPEGE, ano 2, 2005.

APPLE, Michael. W. Freire and the politics of race in education. International Jornal of Leadership in Education, April-June, vol 6, no. 2. Wiscousin: Masison-USA, 2002. Disponível em: https://www.tandfonline.com/doi/abs/10.1080/13603120304821. Acesso em: 18 ago. 2020.

ARROYO, Miguel. Currículo, território em disputa. Petrópolis, Rio de Janeiro: Vozes, 2011.

ARRUTI, José M. Conceitos, normas e números: uma introdução à educação escolar quilombola. Revista Contemporânea de Educação, v. 12, n. 23, 2017.

BAENA, Antônio Ladislau Monteiro (1782-1850). Ensaio corográfico sobre a Província do Pará. v. 30. Brasília: Senado Federal, Conselho Editorial, 2004.

BORTONI-RICARDO, Stella Maris. O professor pesquisador: introdução à pesquisa qualitativa. São Paulo: Parábola Editorial, 2008.

BRASIL. Conselho Nacional de Educação. Parecer CNE/CEB 11/2000. Diretrizes Curriculares Nacionais da Educação de Jovens e Adultos. Brasília, 2000. Disponível em: http://confinteabrasilmais6.mec.gov.br/images/documentos/parecer_CNE_CEB_11_2000.pdf. Acesso em: 25 ago. 2020.

BRASIL. Constituição (1988). Costituição da República Federativa do Brasil de 1988. Brasilia, DF: Presidência da república [2017]. Disponível em: $\mathrm{https} / / /$ legislacao.presidencia.gov.br/atos/?tipo $=\mathrm{CON} \&$ numero $=\&$ ano $=1988 \&$ ato $=\mathrm{b} 79 \mathrm{QTWE}$ 1EeFpWTb1a. Acesso em: 23 ago. 2020.

BRASIL. Lei no $\mathbf{1 0 . 6 3 9}$ de 09 de janeiro de 2003. Altera a Lei no 9.394, de 20 de dezembro de 1996, que estabelece as diretrizes e bases da educação nacional, para incluir no currículo oficial da Rede de Ensino a obrigatoriedade da temática "História e Cultura Afro-Brasileira", 
e dá outras providências. Diário Oficial da União, Brasília, 2003. Disponível em: http://www.planalto.gov.br/ccivil_03/leis/2003/110.639.htm. Acesso em: 22 ago. 2020.

BRASIL. Diretrizes Curriculares Nacionais para a Educação Escolar Quilombola. Resolução nº 08/2012. CNE/CEB. Brasília, 2012. Disponível em: http://www.educadores.diaadia.pr.gov.br/arquivos/File/pdf/diretrizes_nacionais_educacao_esc olar_quilombola.pdf. Acesso em: 25 ago. 2020.

BRASIL. Lei no 9.394, de 20 de dezembro de 1996. Estabelece as diretrizes e bases da educação nacional. Lei de diretrizes e bases da educação nacional. Disponível em: https://www2.camara.leg.br/legin/fed/lei/1996/lei-9394-20-dezembro-1996-362578publicacaooriginal-1pl.html\#: :text=Estabelece\%20as\%20diretrizes $\% 20 \mathrm{e} \% 20$ bases $\% 20 \mathrm{da} \% 20 \mathrm{educa} \% \mathrm{C} 3 \% \mathrm{~A} 7 \% \mathrm{C}$ $3 \% \mathrm{~A} 3 \mathrm{o} \% 20$ nacional.\&text=\%C2\%A7\%201\%C2\%BA\%20Esta\%20Lei\%20disciplina,trabalh o\%20e\%20a\%20pr\%C3\%A1tica\%20social. Acesso em: 20 ago. 2020.

BRASIL. Base Nacional Curricular Comum. Brasília, 2017. Disponível em: http://basenacionalcomum.mec.gov.br/images/BNCC_EI_EF_110518_versaofinal_site.pdf. Acesso em: 22 ago. 2020.

BRANDÃO, Carlos Rodrigues. A comunidade tradicional. In: Cerrado, Gerais, Sertão: comunidades tradicionais dos sertões roseanos (Relatório de Pesquisa). Montes Claros, 2010, p. 347-361.

BRITISH COUNCIL. O ensino de inglês na educação básica brasileira: elaborado como exclusividade para o British Council pelo Instituto de Pesquisas. Plano CDE. São Paulo: British Council Brasil, 2015. Disponível em:

https://www.britishcouncil.org.br/sites/default/files/estudo_oensinodoinglesnaeducacaopublic abrasileira.pdf. Acesso em: 27 ago. 2020.

DIAS, Joel Santos. "Confuso e intrincado labirinto": Fronteira, território e poder na Ilha Grande de Joanes (séculos XVII e XVIII). 2016. Tese (Doutorado em História) Universidade Federal do Pará, Instituto de Filosofia e Ciências Humanas, Programa de PósGraduação em História, Belém, 2016.

FERREIRA, Aparecida de Jesus. Formação de professores: raça/etnia. Cascavel: Coluna do Saber, 2006.

FREIRE, Paulo. Pedagogia do oprimido. 17 ed. Rio de Janeiro: Paz e Terra, 1987.

HADDAD, Sérgio; DI PIERRO, Maria Clara. Escolarização de jovens e adultos: observações específicas sobre juvenilização da EJA e os dois grupos conflitantes existentes, 2000 .

KUMARAVADIVELU, B. The Decolonial Option in English Teaching: Canthe Subaltern Act? TESOL Quarterly, v. 50, n. 1, 2016.

LISBOA, Pedro Luiz Braga. A terra dos Aruã: uma história ecológica do arquipélago do Marajó. Belém, Museu Paraense Emilio Goeldi, 2012. 
MINAYO, Maria Cecília de Souza. Ciência, técnica e arte: o desafio da pesquisa social. In: Pesquisa social: teoria, método e criatividade. 18 ed. Petrópolis: Vozes, 1994.

MIGNOLO, Walter. Educación y decolonialidad: aprender a desaprender para poder reaprender. [Entrevista cedida a] Facundo Giuliano e Daniel Berisso. Revista del IICE, Buenos Aires, n. 35, 2014.

MOITA LOPES, Luiz Paulo da. Identidades Fragmentadas: a construção de raça, gênero e sexualidade na sala de aula. Campinas: Mercado de Letras, 2002.

MOITA LOPES, Luiz Paulo da. Pesquisa interpretativa em linguística aplicada: a linguagem como condição e solução. Delta, São Paulo, v. 10, n. 2, 1994.

MOITA-LOPES, Luiz Paulo da. Inglês no mundo contemporâneo: Ampliando oportunidades sociais por meio da educação. Texto básico apresentado no simpósio Inglês no mundo contemporâneo: ampliando oportunidades sociais por meio da educação. São Paulo: Centro Brasileiro Britânico. 25- 26 de abril de 2005.

PACHECO, Agenor Sarraf. As Áfricas nos Marajós: Visões, fugas e redes de contatos. In: SCHAAN, D. P.: MARTINS, C. P. (org). Muito além dos campos: arqueologia e história da Amazônia Marajoara. Belém: GKNORONHA, 2010.

PENNYCOOK, Alastair. A linguística aplicada nos anos 90: em defesa de uma abordagem crítica. In: SIGNORINI, Inês CAVALCANTI, M. C. Linguística aplicada e transdicilinariedade. Campinas: Mercado de Letras, 1998.

RAJAGOPALAN, Kanavillil. Por uma linguística crítica: linguagem, identidade e a questão ética. São Paulo: Parábola, 2003.

SALVATERRA (Estado do Pará). Proposta da Educação Escolar Quilombola de Salvaterra. Secretaria Municipal de Educação de Salvaterra. 2017.

SKLIAR, Carlos. A inclusão que é "nossa" e a diferença que é do "outro". In: RODRIGUES, D. (Org.) Inclusão e educação: doze olhares sobre a educação inclusiva. [S.1.]: Summus Editorial, 2006.

SCHNEIDER, Sônia Maria; FONSECA, Maria da Conceição Ferreira Reis. Esse é o meu lugar... Esse não é o meu lugar: inclusão e exclusão de jovens e de adultos na escola. Educ. Soc., Campinas, v. 34, n. 122, 2013.

SILVA, Paula de Almeida. Reflexões sobre a raça e racismo em sala de aula: um estudo de caso com duas professores de inglês negras. 2009. Dissertação (Mestrado em Letras) Universidade Federal de Goiás, Goiânia, 2009. 